Mirai. Estudios Japoneses

ISSN-e: 2531-145X

\title{
Fuentes para la Construcción de la Historia: Crónicas desde la Embajada de España en Japón.
}

\author{
Kayoki Takagi ${ }^{1}$
}

Recibido: 31 de enero de 2019 / Aceptado: 15 de abril de 2019

Resumen. El trabajo que se presenta pretende ser una serie de fuentes directas en torno a la evolución de las percepciones sobre Japón desde la década de los setenta del siglo XX hasta los inicios del siglo XXI, desde el privilegiado observatorio de la política diplomática a través de la Embajada de España en Tokio. Dicha labor se enmarca en los coletazos de la celebración de los 150 años del restablecimiento de relaciones diplomáticas entre España y Japón, lo cual ha invitado a la reflexión y al balance. Para ello se ha contado con el testimonio del Exmo. Sr. Embajador D. Antonio de Oyarzábal Marchesi, Exmo. Sr. Embajador D. Juan Leña Casas y del Exmo. Sr. Embajador D. Arturo Pérez Martínez, y se ha recurrido a la entrevista como herramienta, que posteriormente ha sido revisada por los participantes en su forma escrita.

Palabras clave: diplomacia; política; relaciones; cultura; geopolítica.

\section{[en] Sources for the construction of History: Chronicles from the Spanish Embassy in Japan.}

\begin{abstract}
This paper intents to present the evolution of Spanish perceptions of Japan between the 1970 s and the beginning of the $21^{\text {st }}$ century through the diplomatic standpoints of various Spanish Ambassadors in Tokyo. The Spanish Embassy's diplomatic efforts were highlighted at the end of the celebrations of 150 years of the re-establishment of diplomatic relations between Spain and Japan that took place in 2018. The event subsequently led to reflections and assesment by the Ambassadors H.E. Mr Antonio de Oyarzábal Marchesi, H.E. Mr Juan Leña Casas and H.E. Mr Arturo Pérez Martínez who provided their testimonies during a roundtable. The contents of the roundtable was subsequently revised by the speakers in its final written form.
\end{abstract}

Keywords: diplomacy; politics; relations; culture; geopolitics.

Sumario. 1. Imagen de Japón. 2. Estancia en Japón. 3. Después de la estancia: análisis de futuro

Cómo citar: Takagi, K. (2019). Fuentes para la Construcción de la Historia: Crónicas desde la Embajada de España en Japón, en Mirai. Estudios Japoneses 3(2019), 203-217.

Rastreando la bibliografía sobre Japón en español, no podemos encontrar numerosas publicaciones antes de los años 70, pero podemos recordar que un joven diplomático, Francisco de Reynoso y Mateo, permaneció en la Legación de España

\footnotetext{
Universidad Autónoma de Madrid

kayoko.takagi@uam.es
} 
en Yokohama desde 1882 a 1883 y publicó en el año 1904 la obra En la Corte del Mikado. Bocetos japoneses. En ella comenta el autor el disgusto y la desaprobación de sus amigos y familiares sobre el destino en Japón, ya que ir al Extremo Oriente era sinónimo de ir al fin de mundo. ${ }^{2}$ Las experiencias en el país, sin embargo, le regalarían con sorpresa una imagen interesante de un país poco explorado por los turistas extranjeros de la época.

El segundo libro escrito por un diplomático español que tuvo bastante repercusión en la época es Estudios sobre Japón (1895) de Enrique Dupuy de Lōme. Tuvo su destino en el archipiélago en la época en que también residía allí Ernest Satow (1873-1875), diplomático británico y uno de los mejores conocedores de la lengua y de la sociedad japonesa de la época, a quien pedía consejos para comprender mejor la situación de Japón. La obra es un tratado escrito desde su puesto en Washington D.C. en vísperas de la guerra hispano-estadounidense en el que, alarmado, hace un llamamiento por el rápido ascenso del imperialismo japonés junto con el del gigantesco EE.UU.

En 1924 Vicente Blasco Ibáñez publica La Vuelta al mundo, de un novelista. Fue un libro bien difundido y acogido, ya que la sociedad española del momento estaba deseosa de saber del mundo más allá de sus conocimientos generales. Blasco Ibáñez describe su llegada al puerto de Yokohama un año después del gran terremoto de Kantō. Las huellas del desastre sufrido en la zona son aún notables. Su diestra pluma de escritor narra a través de su aguda observación las escenas y describe a la gente que conoció en el viaje, además de realizar una introducción a la mitología japonesa y sus tradiciones antiguas, que suscitaron gran curiosidad entre los españoles. Es de notar, en todo caso, que estas explicaciones están basadas en libros extranjeros no muy contrastados y que, desde el punto de vista actual, cabría poner en cuestión algunas de sus afirmaciones al respecto, pero todo sea dicho con el debido respeto al gran escritor.

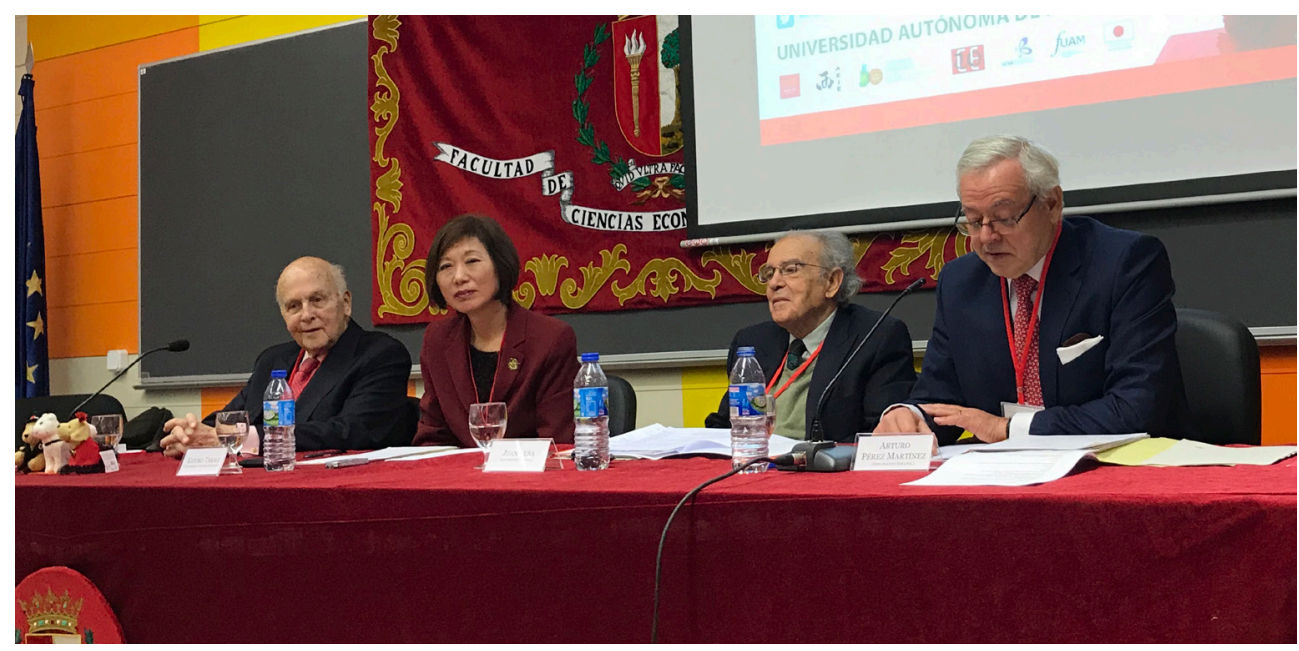

Barlés Báguena, E. (2017): “El diplomático español Francisco de Reynoso (1856-1938) y su recorrido por el Japón Meiji” (2017). En Mirai. Estudios Japoneses, 1, Madrid, pp. 195-215. ISSN-e:1988-2378, http://dx.doi.org/10.5209/MIRA.57112, pp.204, nota 33. 
Más tarde, José María Gironella publicará El Japón y su duende (1964) basándose en su viaje y estancia de siete semanas en Japón, mientras acompañaba al guitarrista Narciso Yepes. Es ya un Japón en plena efervescencia, resucitado de las cenizas tras la Segunda Guerra Mundial. No se puede evitar cierto asombro a la vez que una atracción sincera por una cultura tan lejana y con tintes de exotismo. Hay que tener en cuenta que en esos años España también estaba en plena política aperturista, al igual que Japón.

Tras estos hitos, surgió la pregunta de ¿cuál ha sido el testimonio de nuestros diplomáticos desde entonces? Desde la proximidad real y concreta de nuestra política exterior ¿cuál era la imagen proyectada y percibida de Japón? Por ello abordamos la entrevista a los diplomáticos: Sr. Embajador D. Antonio de Oyarzábal Marchesi, Sr. Embajador D. Juan Leña Casas y Sr. Embajador D. Arturo Pérez Martínez. ${ }^{3}$

Este trabajo pretende ayudar a cubrir el vacío existente sobre el tema al generar conscientemente unas fuentes primarias sobre cuestiones como:

\section{1.- Imagen de Japón \\ 2.- Estancia en Japón \\ 3.- Después de la estancia: análisis de futuro}

\section{1.- Imagen de Japón}

Los puntos tratados en este primer bloque son:

- La imagen de Japón antes de llegar al país.

- La perspectiva con que llegó a Japón.

- El trabajo anterior a su llegada en Japón.

Arturo Manuel Pérez Martínez (Estancia en Japón, 1977-1980, 1981-1984)

Sobre la "Imagen de Japón", empiezo aclarando que en mis dos estancias oficiales en Japón desempeñé el cargo de Secretario de Embajada, lo cual dará un enfoque ligeramente diferente al de quienes estuvieron como Embajadores en Japón. No obstante, razones de índole familiar, las numerosas visitas realizadas y la gran experiencia adquirida me permiten añadir valor a mi participación de forma satisfactoria.

Entrando más concretamente en materia tengo que reconocer que cuando se me destinó a nuestra Embajada en Tokio, allá por mayo de 1977, poco sabía de Japón. Me encontraba prestando mis servicios en la Subdirección General de Europa Oriental en el MAE y hablaba un poco de ruso, por lo que pensaba que sería destinado a Moscú. Mis conocimientos de Japón se limitaban a la información de las enciclopedias, películas y algunos pocos libros. La Vuelta al Mundo de un Novelista, de Vicente Blasco Ibáñez, era bien conocida en España y la leí con deleite. En Japón descubrí alguna inexactitud, tal vez derivada de las fuentes utilizadas por el autor. La novela Shogun de James Clavell y A Diplomat in Japan de Sir Ernest Satow (suficientemente conocido por su célebre "Guía") quedarían para después de la incorporación. El cambio de destino no pudo ser más satisfactorio. Coincidí en la Escuela Diplomática con algunos diplomáticos japoneses. Especialmente grato me resultó conocer al hoy Embajador jubilado Motohide Yoshikawa. El Sr. Yoshikawa continúa siendo un gran

La entrevista tuvo lugar en las dependencias de la Universidad Autónoma de Madrid, 21/11/2018. 
amigo de los tres. Al inicio me llevó a un restaurante japonés y me permitió conocer a varios magníficos amigos suyos que me abrieron numerosas puertas. Más tarde sería el padrino de mi boda con una japonesa, Kayoko Takagi.

Cuando llegué a Tokio mi deseo podía resumirse en aprender, adquirir experiencia y cumplir para iniciar y llevar a cabo una buena carrera profesional. Pero no todo iba a ser coser y cantar. Japón estaba considerado como puesto $\mathrm{C}$ en nuestra escala (A, B y C), es decir, difícil, y así lo estuvo en mis dos destinos, seguramente por la lejanía de España (el shock de mi familia cuando se enteraron de que iba allí), por la carestía de la vida, por la vivienda de reducidas dimensiones, por el clima (que me hizo comprarme un coche al segundo día de llegar andando empapado al trabajo por la tremenda humedad), los frecuentes terremotos y el difícil idioma que, por cierto, se me desaconsejó aprender y de lo que nunca estaré lo suficientemente arrepentido, si bien en inglés la comunicación estaba garantizada en general. Actualmente Tokio es puesto B. Tal vez el mejor conocimiento del país y las numerosas cosas buenas a que se tiene acceso ahora han facilitado esta consideración. De todas formas, el trabajo era exigente y no permitía tener grandes iniciativas. Más bien lo aconsejable era secundar la iniciativa de los japoneses, según nos recomendaba el embajador.

A mi incorporación me encontré con una Sección Cultural que funcionaba perfectamente. La oficina estaba muy ordenada y no tuve, sino que actualizar alguna información. Me pude beneficiar, por tanto, de la labor de mi predecesor y de los contactos que la Embajada mantenía con universidades, lectores de español, hispanistas, escuelas de flamenco, de guitarra, de idiomas, etc.

\section{Juan Bautista Leña Casas (1980-1984, 1999-2003)}

Antes de llegar al país, la imagen que yo tenía de Japón era tópica, fragmentaria y poco rigurosa. Predominaban ideas relacionadas con San Francisco Javier, las gueisas [sic], los samuráis y su código ético y de combate, el hara-kiri, la Segunda Guerra Mundial, tal como presentaba el conflicto el cine norteamericano, los kamikazes y poco más. Mi padre creció de lleno en la etapa de modernización del Emperador Meiji y era frecuente que alabara en casa la disciplina y los logros del Japón imperial, especialmente, sus victorias inesperadas en la guerra chino-japonesa y en la ruso-japonesa. Era una forma de idealización del Japón que se abría al mundo, al tiempo que se convertía en gran potencia asiática en pie de igualdad con las potencias occidentales. Mi padre, médico de profesión y gran lector, admiraba la disciplina, la educación y los fuertes vínculos de la familia japonesa. En nuestra enseñanza secundaria Asia tenía poca presencia y lógicamente nuestras preocupaciones no se orientaban en esa dirección. La formación universitaria, las lecturas, la prensa de dentro y fuera de España, algunas películas fueron ampliando mi interés por Asia y Japón de manera gradual. Pero siempre desde la distancia y un interés bastante superficial. La lectura de La Vuelta al mundo de un novelista, de Blasco Ibáñez, y la tragedia del terremoto de 1923 me acercaron a Japón de una manera más reflexiva. Pero mi aproximación a Japón no cambió hasta mi primer destino diplomático en Los Países Bajos, cuyas relaciones con Japón habían sido intensas. Holanda era un pequeño país, que había sabido crear un gran imperio oceánico de raíces fuertemente comerciales. En La Haya comenzó también mi interés por los grabados japoneses (ukiyo-e), que aún continúa.

En realidad, el primer destino asiático que yo solicité en el Ministerio de Asuntos Exteriores fue China, pero le fue asignado a un compañero mejor situado que 
yo en el escalafón. Japón, al comienzo de los años setenta del siglo XX, no era un destino fácil, ni tampoco difícil. Era, simplemente, un destino lejano. Las relaciones hispano-japonesas eran escasamente significativas. Las comerciales no sumaban mucho, mientras las culturales resultaban más atractivas, porque permitían mejor la inmersión en la vida japonesa, la cultura, el arte y las universidades, donde la lengua española estaba bastante presente. Nada parecida a la situación en España, donde los estudios japoneses brillaban por su ausencia.

De mis predecesores en Japón me han interesado varios de ellos, pero especialmente el Ministro de la Legación de España, Méndez de Vigo, a quien cupo en suerte lidiar con un período difícil y complejo, tanto de la historia de Japón, como de la de España: la cuestión de Manchuria en la Sociedad de las Naciones en Ginebra, el golpe de estado de oficiales jóvenes en Tokio en febrero de 1936, la misma época de la Guerra Civil española. La trágica aceleración histórica que llevó al mundo al estallido de la Segunda Guerra Mundial en Europa y en el Pacífico. Esos fueron también "momentos estelares de la humanidad".

Antonio de Oyarzábal Marchesi (1990-1994)

Mi destino a Japón me sobrevino como una total sorpresa caída del cielo. Es más, me habían llegado rumores desde "la superioridad" de que iban a ofrecerme una embajada en Europa, y en esa espera estaba cuando el propio Ministro Fernández-Ordoñez, en un vuelo a Ottawa, donde me encontraba, me anuncia que Tokio iba a ser mi próximo puesto. Mis conocimientos del país eran limitados, pero mi interés por su cultura y por su historia -pasada y reciente - eran vivas, siempre azuzado por un atractivo hacia lo distante, lo diferente, lo ignoto... para quien ha vivido sobre todo en el entorno de nuestra civilización occidental. Eso sí, todo este interés se había visto muy aumentado después de la visita de Estado de nuestros Reyes en 1980, y de cuyo séquito había formado parte como Director General de la Oficina de Información Diplomática.

La primera persona a la que pude comentar -en secreto- la buena noticia de mi próximo destino fue a Kayoko Takagi, que, junto a Arturo Pérez, su marido, estaban destinados en la capital canadiense. La reacción inmediata de esta magnífica amiga fue darme una serie de importantes consejos -luego reiterados en una larga cartaque procuré seguir al pie de la letra y a los que debo cualquier atisbo de éxito que pueda atribuirme. Evidentemente sus consejos me fueron muchísimo más útiles que todo el expediente sobre las relaciones hispano-japonesas del Ministerio y que leí a marchas forzadas antes de mi traslado.

La Embajada en Tokio era ya en aquellos tiempos codiciada entre mis colegas, así que la oferta que se me hacía colmaba con creces mis aspiraciones. Era un puesto lleno de posibilidades de lucimiento, sin problemas candentes sobre la mesa, magnífico punto de observación de ese mundo tan desconocido entonces como el Lejano Oriente, en un país de un desarrollo espectacular que se hacía presente en forma de grandes inversiones industriales en toda Europa, España incluida. Hasta el factor distancia que había supuesto cierta dificultad en su día, se veía entonces muy aminorado con el vuelo diario del "jumbo" de Iberia y con los modernos métodos de comunicación con que contábamos. 


\section{Estancia en Japón}

Relatadas algunas experiencias sobre la vida en Japón, como diplomáticos con obligación de servir a su país desde el exterior, en concreto desde Japón, fueron preguntados sobre el panorama político encontrado por cada uno de ellos, qué eventos culturales relevantes tuvieron lugar durante su estancia, los acontecimientos que les tocó vivir allí y, en definitiva, qué relaciones bilaterales consideraba que existían en su época.

Resulta interesante anotar dos grandes similitudes entre España y Japón, como es el sistema político, comparten una monarquía parlamentaria, y la tardía apertura a la internacionalización. Había unas relaciones muy cordiales entre España y Japón a través del intercambio entre las dos Casas Reales, pero, globalmente hablando, las relaciones políticas, económicas y culturales eran bastante escasas. Como nota simbólica podemos mencionar el retraso en el ingreso en la Organización de Naciones Unidas: España ingresó en la ONU en el año 1955 y con un año de diferencia lo haría también Japón. Este hecho, sin duda, influía en el día a día de nuestras relaciones.

A. O.:

Mis cuatro años largos de embajador en Tokio vinieron marcados por la circunstancia decisiva de las celebraciones del "Año de España" a lo largo de 1992. Había de nuestro país un conocimiento muy elemental, mezcla de una vaga simpatía generalizada próxima al baile flamenco, a la música de guitarra, al romanticismo de castillos y monumentos y poco más. Una imagen de cierto atraso tecnológico en comparación con otros países europeos, y la lejana impronta de figuras como San Francisco Javier o el mito de Don Quijote de la Mancha. Parecía totalmente descabellado para aquellos japoneses el reto que habíamos asumido de organizar en un mismo año una gran Exposición Universal y unos Juegos Olímpicos, cuando el propio Japón había marcado un lapso de ocho años entre los dos eventos para reponerse de las inversiones y complicaciones organizativas de ambos. El éxito de nuestros dos desafíos simultáneos fue en este sentido determinante. España se "apareció" ante los ojos de los atónitos japoneses como un país moderno, atractivo, que no había perdido ni un ápice de su encanto histórico y folclórico, pero que mostraba de pronto una cara desconocida de modernidad y eficacia.

Si en todas partes ese «Año de España» constituyó un éxito de imagen, en pocos sitios como Japón pudieron resultarnos más rentables las grandes inversiones y esfuerzos que hicimos. No solo los dos años previos vimos televisiones, radios y periódicos dedicar crecientes espacios a cuanto se refería a «lo español», sino que la «resaca» posterior marcó nuestra estancia y lógicamente el tenor de las relaciones entre nuestros dos países. Vivimos en una auténtica cresta de la ola. Y como remate de este periodo feliz de nuestra estancia y destino, fuimos testigos de una espectacular visita de Estado de los Emperadores a España, concretamente a Mallorca, Madrid, Salamanca y Barcelona.

J. L.:

Yo tuve la suerte, en lo que se refiere a mi trabajo en la Embajada, de combinar dos ocupaciones que permitían el contacto frecuente y directo con sectores importantes de la sociedad japonesa: las relaciones culturales y la política interior. Había que informar puntualmente a Madrid de ambas cosas, ya fuera por telegrama o despacho, y ello exigía la lectura de la prensa, lo mismo que un abanico de contactos en el Ministerio de Asuntos Exteriores (Gaimushō) y en las dos cámaras del Parlamento 
o en los distintos ministerios y agencias estatales, lo cual no siempre era fácil. Allí aprendí que la mirada al mapa desmitifica muchas cosas. Así, me sorprendió ver en el Ministerio de Asuntos Exteriores un mapa con Japón en el centro y España en uno de los extremos. Ahí me di cuenta que lo de Extremo Oriente depende de donde se sitúa el observador.

El Ministerio en Madrid prestaba una atención relativa a nuestro trabajo. Y eran pocos los intercambios de visitas. Aún no había tenido lugar la incorporación de España a Europa y nuestra agenda bilateral era más bien menguada: la negociación del convenio aéreo o el cultural, la celebración de alguna gran exposición española en Tokio, la prohibición de exportar naranjas y limones a Japón por la mosca mediterránea o temas pesqueros. Además de seguir la política exterior japonesa, siempre tan de la mano de los EE.UU.

Lo que si constituyó un acontecimiento importante de nuestras relaciones bilaterales fue la visita de los Reyes de España a Japón en el otoño de 1980. Esa visita me ayudó mucho, porque yo había llegado a Japón desde Holanda tan solo tres meses antes y fue, por tanto, mi bautismo de fuego en ese destino diplomático, en el que tanto aprendí y disfruté.

El dinamismo de la sociedad japonesa, su organización empresarial, su potencia industrial, los hábitos de consumo de la población, la disciplina de estudiantes y trabajadores, y la cohesión familiar causaron en mí un fuerte impacto. Europa, en comparación, parecía un continente en crisis. No hay que olvidar que era los años en que el ascenso de Japón parecía imparable. Precisamente, los años en los que el profesor norteamericano Ezra Vogel escribió un best seller que todo el mundo leía y comentaba: Japan as number one. Japón era la affluent society del momento. Después vendría el estallido de la burbuja inmobiliaria y financiera y toda una "década perdida", en la que los sucesivos gobiernos no quisieron o no pudieron adoptar las necesarias medidas contra la crisis. Japón es una sociedad de consenso o de armonía, si se quiere, con sus ventajas e inconveniencias, pero en estos últimos años se ha escrito sobre "las paradojas de la armonía", entendida como consenso, ya que el consenso impide progresar, precisamente porque satisfacer a todos empuja las sociedades al estancamiento. Algunos analistas subrayan que este es uno de los problemas de Japón en este momento.

Mi adaptación a la vida japonesa se produjo sin traumas, ni mayores dificultades, tal vez, porque la cobertura diplomática facilita las cosas. La sociedad japonesa no resulta fácil para los propios japoneses, ni tampoco para los extranjeros que se mueven fuera del circuito diplomático, especialmente los que desenvuelven su vida fuera de las grandes multinacionales.

Muchos sectores de la vida japonesa han llegado a interesarme profundamente durante mi estancia en el país y aún hoy me interesan sobremanera: el plus de refinamiento que los japoneses añaden a las manifestaciones artísticas o espirituales que llegan de fuera, la preferencia por lo simple y natural, su pasión por la belleza efímera y transitoria, la gran disciplina social ante la adversidad y la catástrofe, el gusto por la información y el estudio, la complejidad/simplicidad de su gastronomía, la pervivencia de usos sociales que introducen elementos de serenidad y calma en la vida colectiva, su actitud ante la muerte, la religión y la naturaleza...

Otra cuestión que es difícil encontrar en otros países al mismo nivel que en Japón es la endogamia en la clase política. El número de hijos, yernos o familiares que tienen asiento en las cámaras o en los gobiernos o en los ministerios o agencias 
administrativas supera con mucho la práctica admisible en la materia en otras democracias desarrolladas. Auténticas sagas familiares, a menudo con ancestral asidero territorial, se pasan el escaño o los empleos como si de propiedad familiar se tratara.

A. P.: En cuanto a mi estancia en Japón, hago las siguientes puntualizaciones sobre lo que me llamó más la atención de la vida japonesa:

En lo profesional me di cuenta de su concienzudo trabajo, siempre aspirando a la perfección, eso sí, a base de mucho esfuerzo y repetición. Comento con cierta ironía el uso del "hachimaki", tira de tela que ciñe la frente del que lo lleva en la convicción de que apretar las sienes anima a trabajar más, manteniendo al actor más alerta y despierto. Pongo el ejemplo de los manifestantes ante la Embajada de la entonces Unión Soviética que lo llevaban con su sol naciente en el centro para mejor protestar, gritar "eslóganes” (¡menudo palabro!) y vociferar de la manera más audible posible.

En lo personal he de resaltar la educación y la cortesía de que siempre hacen gala los japoneses, refinamiento, limpieza, seriedad y curiosidad por lo extranjero. También dedico un comentario a la mujer que trabaja y asiste a las reuniones con hombres. El hecho de que no sea muy locuaz, antes bien, discreta, no quiere decir que no goce de una esmerada educación y formación. No conviene confundirse porque hay grandes ejecutivas que tienen mucha importancia en la vida y en la economía del país, aunque no lo parezca.

Por lo tanto, la adaptación a la vida japonesa fue bastante fácil. No solo la gente es amable y con deseos de agradar, sino que todo funciona y aquí hay que destacar el rasgo de la puntualidad, característica bien marcada de los japoneses, con la que hay que estar a la altura. El tema del idioma tiene dos dimensiones. No se puede dominar a la perfección porque descoloca al interlocutor japonés. Por otra parte, ayudarse de un intérprete tiene muchas limitaciones. Pocas veces son excelentes. El idioma inglés, que muchos japoneses conocen, pero menos se atreven a hablarlo, también presenta dificultades, aunque se suele salir del paso.

La adaptación fue fácil por lo anteriormente señalado. Otra cosa es la eventual integración en la sociedad japonesa. Se puede tener buenos amigos, pero pertenecer al grupo es difícil por cuestiones culturales, idiomáticas y, naturalmente, geográficas, aunque pueden ser fundamentales las familiares.

Lo que más me interesó de mis dos estancias en Tokio, en lo profesional ha sido aprender de la política exterior japonesa, con especial mención de sus relaciones con los EE. UU., con Rusia y con el resto de Asia. Igualmente he podido aprender bastante de política exterior española principalmente en esa zona geopolítica. Lo que más colmó mis aspiraciones fue ocuparme de las relaciones culturales y entrar así en contacto con artistas, hispanistas, lectores, universidades, etc. Pude ser testigo también de algunas importantes visitas que mejoraban el clima de buena voluntad entre nosotros, al igual que permitían avanzar en los temas.

En lo personal fue y es una gran satisfacción conocer tan interesante país, amigos, viajes, sitios, historias.

Acontecimientos relevantes que presencié fueron, por ejemplo, el Canje de Notas de 8-11-80 por el que se establecían servicios aéreos regulares entre nuestros dos países, después de gran insistencia española. También fue particularmente grato participar en la labor de tan pujante prefectura, como la de Hyōgo, que movilizó recursos y tiempo para organizar magníficas exposiciones. Además, se consiguió destinar a un becario de dicha prefectura al entonces Museo Español de Arte Contemporáneo y hermanarlo con la ciudad de Kobe, capital de la prefectura. Tras el terremoto de 
dicha ciudad de 1995, las autoridades prefecturales me distinguieron con su reconocimiento dentro del denominado "Plan Fénix". También me cupo la satisfacción de presenciar el hermanamiento entre las ciudades de Yamaguchi (primer sitio de Japón que pisó San Francisco Javier) y Pamplona, de 9-2-1980 y, por fin, el Acuerdo Cultural de 5-3-1982.

Por su parte, en general el Ministerio de Asuntos Exteriores nos apoyaba, aunque sin estridencias. Había un Subdirector General (de Pacífico) que leía nuestros despachos y telegramas y hacía algunos comentarios (pocos) cuando le parecía oportuno. El Director General de Relaciones Culturales también nos tenía en cuenta, aunque se empezaba a notar la falta de dinero para nuestras actividades en Japón. En vista de eso la Embajada pedía poco, tal vez el mínimo imprescindible. En mi segunda estancia hubo cambio de interlocutores y Madrid nos pidió no bombardear con temas diversos (éramos más a informar y otro el que consideraba las prioridades) y concentrarnos.

El caso es que lenta, pero gradualmente, la atención de Madrid se hizo mayor y más positiva y, como he señalado antes, los temas se movían sobre todo a base de visitas, aunque no siempre fuera así.

Al comentar sobre el mapa del mundo con Japón en el centro, me complace informar sobre otro hecho por los australianos, que pude descubrir en mi destino de Sídney (1999-2003) un mapa mundi con Australia en el centro, pero boca arriba (para nosotros, los del hemisferio Norte) y el resto de los países en ambos extremos. Y es que debemos abandonar la concepción eurocéntrica del mundo porque hay muchísimos países más allá.

Otro comentario lo dedico a la importancia política de España, al no ser miembro aún de la CEE. Eso implica ocupar un lugar más discreto en las reuniones y tener menos acceso a determinada información, cosa que cambiaría al producirse nuestro ingreso en 1986, lo que nos abrió no pocas puertas.

K. T.: Una pregunta más sobre las experiencias vividas en Japón. En cuanto a las respuestas por parte del gobierno español a las iniciativas de las embajadas, ya hemos oído que a veces, con las visitas de los Reyes, de las personalidades importantes y de los eventos extraordinarios se potencian y se produce un flujo de contacto considerable, pero, por otro lado, en el día a día las comunicaciones son más bien escasas o complicadas. En el pasado, un embajador japonés comentó que las relaciones bilaterales España-Japón eran como «un amor no correspondido». ¿Quién no correspondía? Decía que Japón deseaba estrechar las relaciones con España, pero ella no respondía. Esta frase fue muy repetida en muchas de sus intervenciones durante su estancia. Sin embargo, por parte española se demostraba muy educadamente que eso no era verdad, que España también deseaba lo mismo, pero materializar esos deseos en hechos era una tarea complicada. Sabemos que España se encuentra en Europa y su aspiración histórica de primer orden era formar parte de la Unión Europea (entonces CEE) y, por otro lado, existe una especial conexión con Iberoamérica cuyas relaciones con España prevalecen sobre otras.

Hace ya algún tiempo, vino el presidente de la ASEF (Asia Europe Foundation) a Madrid y dio una charla en la Fundación Ortega y Gasset. Dijo que España no debería perder de nuevo el tren frente a otros, en cuanto a la política con Asia. Se refería a la situación anterior a los 90 , en que la región asiática recibía mucha cooperación europea para el desarrollo, panorama en el que la presencia de España era aún escasa. Su mensaje era que, acercándose al año 2000, cuando todos los países 
del mundo estaban mirando a los países del sudeste asiático como tigres asiáticos, España debería hacer un esfuerzo para estar a la altura de los otros socios europeos.

Estamos hablando de un hecho casi del pasado ya que el panorama ha cambiado mucho hoy día, pero me gustaría oír sus opiniones al respecto.

A. O: Hay algo de cierto en el hecho de que España y Japón han sido distantes, aunque no en el trato sino en lo práctico. Cómo materializar una relación cordial en unas actividades comerciales no era una tarea fácil. Muchas veces, atraer empresas españolas que aprovecharan el buen ambiente político era predicar en el desierto. Lo mismo pasaba en el terreno cultural. En la concesión de las becas, el alto coste de cada beca era un problema. Sin embargo, las cosas van cambiando rápidamente. Había una relación especial entre las Casas Reales. La última visita de los Emperadores a España fue un buen ejemplo de cómo se pueden hacer las cosas bien para ambos países. Estos gestos y estos símbolos evidentemente tienen un reflejo inmediato. Si nos preguntásemos si hemos aprovechado todas las ocasiones, visto desde ahora, pues no lo hicimos tan mal. Ahora las relaciones son mucho más intensas y nos conocemos mejor.

Creo que alguna queja de la Embajada del Japón de que era un amor no correspondido, esto no es cierto. En la parte oficial y en lo relacionado a los reyes siempre había una debilidad por Japón. Cuando yo estaba en Japón hubo varias visitas tanto de parte española como de parte japonesa entre los miembros de la familia real y la familia imperial que derivaban en su conjunto en una buena relación bilateral. Teniendo en cuenta el exotismo que suscitábamos ambos en los años 90, podemos decir hoy que estamos en buen camino.

J. L.: Estoy bastante de acuerdo con los términos que ha utilizado Antonio. Las relaciones han tenido un recorrido largo y positivo. Es verdad que la percepción de España en Japón, de manera seguramente correcta al margen del aspecto cultural, ha sido algo negativa porque Japón es un caso de modernización acelerada para evitar que le sucediera lo que le pasó a China en el s. XIX. En el período Meiji se quemaron etapas para llegar a donde llegaron. España no estaba en esta modernización. Todos los grandes países europeos estuvieron en esa modernización de Meiji de manera activa e importante. De ahí partió la imagen de que España era un país en decadencia, cosa que efectivamente era así porque el 98 marcó esa decadencia. Justamente, España se marchó de Asia prácticamente, aunque manteníamos relaciones con Japón y China. Aparte de eso, como decía Antonio, las relaciones de la Casa Real y la Casa Imperial eran estrechas. A pesar de la distancia, que se viajaba solo en barco, el número de visitas del alto nivel durante los años de Meiji y Taishō fue bastante considerable. Había una sintonía.

Después, las relaciones discurren por cauces modestos. Cuando yo llegué a Japón, los temas eran cefalópodos y el debate sobre las naranjas, que no había manera de arreglar. Ahora la relación es más rica y diversificada.

En el terreno cultural, es verdad que los japoneses han hecho más, pero cuando uno ve en las librerías de España los libros sobre Japón, por ejemplo, los de Satori Ediciones, se ve que en España se publican muchas cosas de alto nivel sobre Japón: historia, antropología, economía, novela, arte, etc. Esto indica que la sociedad española presta una atención creciente y se puede decir, preferente a Japón. Por otra parte, Japón sigue siendo difícil porque es un país industrial de una potencia extraordinaria. En este sentido, las empresas españolas industriales en Japón poco pueden hacer salvo que encuentre algún nicho de mercado especializado. Ahora, podemos 
competir en alimentación, diseño, moda entre otros. Creo que la relación va marchando y está cada vez más llena de contenido. Los españoles cada vez saben más de Japón y también van afinando su conocimiento los japoneses sobre España. Creo que la relación está bien encaminada.

K. T.: Por mi parte, recuerdo que sufrí una grave contrariedad cuando Iberia cerró su oficia en Tokio en 1998. La habían instalado en el centro del elegante barrio de Harajuku. Esto ocurrió un año después de la visita oficial del Presidente del Gobierno de España a Japón en 1997 y que unos meses más tarde se celebró en Tokio la "Expoconsumo" dedicada a Valencia, con la presencia del Príncipe de Asturias, Don Felipe, e, incluso, Julio Iglesias fue invitado para reforzar la exposición española. El esfuerzo que hizo el Gobierno español para con el mercado japonés fue notable. Sin embargo, el vuelo directo que databa ya de 12 años se perdió justo después. Esto afectó mucho y muy negativamente a las relaciones comerciales y culturales entre ambos países. Desde entonces, tuvieron que pasar 18 años hasta que se restauró dicho vuelo en 2016. Es un buen ejemplo de que la política de comercio exterior que plantea el gobierno no siempre sale bien parada cuando no hay una voluntad consensuada de esfuerzo continuado conjunto.

Por otra parte, en el terreno cultural España seguía siendo un país de atracción cultural y turística. Por mucho que intentemos decir que España no es un país de toros y pandereta, la imagen de España que tienen los japoneses hasta hoy la constituyen la guitarra, el flamenco, que se practica muchísimo en ese país y, tal vez, ahora la gastronomía.

A. P.: En respuesta al comentario sobre los tópicos que impregnan nuestras relaciones, respondo que los estereotipos no nos perjudican. No va en detrimento nuestro que aparezca una "bailaora" en una etiqueta de queso, por poco positivo que eso pudiera ser, pero, precisamente por eso, destaqué el amor por la música y la danza española por parte de los japoneses. Hay numerosas academias donde aprender, eso sí, a base de mucho esfuerzo y repetición. Hay quien consigue buenos resultados, aunque la mayoría tenga margen para mejorar principalmente por falta de "duende". En todo caso hay mucho interés por uno y otro país y eso hace que en España el arte japonés despierte tanta curiosidad como admiración. Somos superpotencias culturales y eso se deja ver en todo momento.

A. O.: Es anecdótico, pero una manera de medir un poco lo que ha sido el progreso de nuestra presencia en Japón y de la japonesa en España es la gastronomía. Antes de irme a Japón había pocos restaurantes japoneses en Madrid y, sin embargo, hoy podemos encontrar uno en cada esquina. La invasión de la cocina japonesa es impresionante. El poder de la gastronomía es cada vez mayor. Da un poquito la medida de la intensificación de las relaciones entre España y Japón.

K.T.: Hablemos del papel de la Embajada para apoyar la iniciativa cultural, y el mecenazgo compartido entre las instituciones oficiales y el sector comercial.

J. L.: Hay algunas cuestiones que afectan a la sociedad japonesa que siempre me han llamado la atención: las peculiares formas de mecenazgo y de participación de los medios de comunicación y grandes almacenes en la organización de exposiciones, recitales, conciertos, creación de museos y orquestas, etc. En un ámbito estrictamente privado. Una singular combinación de promoción comercial y arte, en el más amplio sentido de la palabra. En España decían los clásicos "deleitar aprendiendo" y en Japón podíamos decir "deleitar consumiendo". 


\section{Después de la estancia y el análisis del futuro}

K. T.: Tras la experiencia en Japón, cada uno ha seguido su carrera diplomática y han sido destinados a diferentes puntos del mundo, pero, una vez que habían vivido en Japón, su percepción del país en el contexto global podría haber cambiado. Por ejemplo, el caso del Embajador Oyarzábal que ha sido Embajador en Washington D.C. Todos sabemos que la relación Japón-EE. UU. es algo muy notable y especial. En este sentido, nos interesaría saber cómo veía el embajador español esta relación desde el puesto de Washington.

A. O.: Cuando tras un destino bien agradable de dos años en Copenhague me fue ofrecida la Embajada en Washington, siempre he pensado que este puesto soñado por cualquier profesional de nuestro Servicio Exterior, se lo he debido a mis avatares en Japón y, a las oportunidades de éxito que el puesto de Tokio y la circunstancia de 1992 me ofrecieron en bandeja. Así culminé una carrera de ocho lustros con toda la satisfacción que conllevan puestos de la relevancia de Tokio y de Washington. Mis días en Japón habían coincidido con un momento especialmente difícil de las relaciones entre el país y Estados Unidos. La superpotencia que había marcado indeleblemente la vida política japonesa desde la terrible posguerra, se veía entonces enfrascada en una injusta campaña mediática de "Japan bashing", de características bastante xenófobas. Sin embargo, cuando unos años más tarde llegué a Washington esa actitud había sido ya ampliamente superada y Japón había incluso pasado de ser el país "aliado a la fuerza", como plataforma de bases militares mirando a China, a ser considerado un socio y amigo dispuesto a colaborar en el objetivo común de contener el tsunami económico, tecnológico y político que se avecinaba desde el poderoso vecino regional. Cualquier resabio hacia Japón se había diluido ante la urgente necesidad de cerrar filas, y, por inspiración sobre todo de Tokio, comenzaba a gestarse el amplio acuerdo llamado después TTP firmado, pero, desgraciadamente, puesto en entredicho actualmente por la actitud del Presidente Trump y su Administración.

K. T.: El embajador Juan Leña ha sido embajador en los tres países de Asia Oriental, China, Japón y Corea, cosa que no ocurre con muchos diplomáticos. ¿Esta experiencia cambió su percepción sobre los asuntos de Japón? y ¿cuál es tu análisis de las relaciones entre estos países?

J. L.: Indudablemente, la percepción cambia cuando se tienes una experiencia prolongada en el país, ya sea en Japón o en cualquier otro lugar. Además, yo he tenido la oportunidad de ser Secretario de Embajada y Consejero entre 1980 y 1984 y la de desempeñar el puesto de Embajador por espacio de tres años y medio entre abril de 1999 y octubre de 2004. En mi primera etapa japonesa, las relaciones hispano-japonesas tenían menor contenido y España no era miembro de la UE. El nivel de interlocución con las autoridades japonesas tenía estricto carácter bilateral, mientras que, como Embajador, España contaba con su condición de miembro de la UE. En la primera mitad de 2002, España asumió la Presidencia de la UE y nuestra acción en Japón era más visible y eficaz. España hablaba en nombre de la UE y contaba con la colaboración de los países miembros y el respaldo de las instituciones europeas. Se veía en los contactos con las autoridades japonesas en los más diversos ámbitos (comercial, cultural o de seguridad). Además, en esos años las empresas españolas habían experimentado un importante proceso de internacionalización y la relación bilateral también comenzó a cambiar cualitativamente. Fueron los años del Plan Asia, que implicaba una nueva mirada de España al continente asiático y, concretamente, a Asia Oriental. 
En esos tres países se siente rápidamente que se está en una de las partes más sensibles del globo, en términos económicos, comerciales, tecnológicos y de población, lo mismo que en el campo de la seguridad. Además, la primera potencia del mundo y también la primera economía a nivel global, los Estados Unidos, desempeña un papel capital en la región desde el final de la Segunda Guerra Mundial. China, la gran potencia emergente, es un actor global de primer orden, mientras Japón es la tercera economía a nivel mundial por el volumen de sus recursos financieros, capacidad industrial y nivel tecnológico. En Asia Oriental se está ante la mayor concentración de poder económico y militar que ha visto la historia, incluida la capacidad nuclear de varios de esos actores, como el problema nuclear de Corea del Norte ha puesto de manifiesto. Tampoco faltan otras tensiones geoestratégicas, de las islas Kuriles y del mar de China Meridional, que pueden tener efectos desestabilizadores, si no son bien gestionadas por los países de la región. Hasta ahora han prevalecido el diálogo y la cooperación, pero no hay que descartar errores de cálculo que puedan desestabilizar el frágil equilibrio regional y afectar a la economía y la seguridad globales.

K. T.: El Embajador Arturo Pérez ha visitado regularmente Japón durante cuatro décadas hasta la fecha y ha tenido destinos en Washington, Europa y, en la zona, Australia y Bangladesh, ¿a qué comprensión global ha llegado en cuanto a la nación Japón?

A. P.: Destaco el hecho de que Japón desea mantener buenas relaciones con todo el mundo, pero, especialmente, con los productores de materias primas. Japón pertenece al bloque occidental, pero también es un país asiático y comienza a participar con los países de la zona en todas las empresas posibles, sin complejos y sin tanto recelo por parte de los otros.

Al hilo de lo señalado por el Embajador Oyarzábal, debo indicar que, cuando llegué al nuevo puesto de Washington procedente de Tokio, se oían con insistencia múltiples quejas contra Japón por el tema de las fricciones comerciales. Y es que en los años 80 Japón empezó a acumular grandes superávits comerciales beneficiándose, entre otros factores, del principio de libre empresa americano. Se llamaba, pues, a Japón a que limitara sus exportaciones, lo que, por otra parte, no era posible por la gran demanda existente en América. El caso es que EE. UU. veía comprometida su supremacía. Japón, además, empezó a hacerse con el 20\% de la deuda americana y comenzó a sufragar programas federales y locales para la satisfacción de sus responsables inmediatos. Estaba claro que las economías habían dejado de ser complementarias y las relaciones comerciales sufrían de mucho altibajo. Pero a ambos países les interesa la estabilidad. A todos los países más bien, dadas las magnitudes en que nos movemos.

Con Canadá las relaciones son muy buenas y, al contrario de lo que ocurría con EE. UU. aquí el superavitario es Canadá, que vendía a Japón, cuando estuve destinado en Ottawa, madera, pulpa y carbón a cambio de automóviles principalmente. Con Canadá las relaciones han sido siempre positivas. Incluso, después de la Segunda Guerra Mundial, en que trató de suavizar las medidas de castigo al vencido. Aquí sí que las economías son complementarias y las relaciones muy amistosas y estables.

Igual ocurre con Australia, donde también me cupo la suerte de estar destinado de 1999 a 2003. Allí igualmente, se registraban superávits dentro del abundante comercio a base de minerales y productos agrícolas para Japón a cambio de productos manufacturados. Japón era entonces el segundo cliente después de EE. UU. Lo estrecho de las relaciones comerciales había dado lugar a muy íntimas relaciones políticas 
y de amistad, con numerosos estudiantes de japonés en las universidades e, incluso, en las escuelas.

En cuanto a Bangladesh, tuve la suerte de abrir la Embajada de España en Dacca en 2008 y me pude percatar de la gran importancia que Japón concedía a ese país. La relación comercial está, naturalmente, desequilibrada a favor de Japón, pero este considera que se trata de un mercado de 160 millones de habitantes y de una economía que crece al $6 \%$ anual, lo que sin duda sacará al país de la pobreza a bastante corto plazo. En 2017 la AOD japonesa ascendió a los 1.766,89 billones de dólares que se destinan principalmente a infraestructuras de transporte (puertos, puentes, tráfico por carretera -allí el tráfico es muy problemático_-), sanidad, agua y energía, entre otros sectores.

España y Japón se ven con simpatía y cordialidad recíproca. No existen contenciosos y las relaciones bilaterales operan sin sobresaltos. Japón valora el hecho de que España pertenezca a la UE y que se pueda colaborar con ella en terceros países. Tal vez España pudiera cubrir huecos que eventualmente se produjeran por causa del "Brexit" o de la retirada de EE. UU. del TPP. En fin, nuestro comercio se va equilibrando paulatinamente y cuenta con elementos institucionales de apoyo (Asociación para la paz, el desarrollo y la innovación, Ligas parlamentarias de la amistad, Foro España-Japón y Comisión Conjunta de economía entre las Cámaras de Comercio) y con un creciente número de turistas en ambos sentidos, favorecido por el restablecimiento del vuelo sin escalas Madrid - Tokio, afición por la cultura, gastronomía, etc. Será muy positiva la entrada en vigor del Acuerdo de libre comercio entre la UE y Japón del que ambas partes se van a beneficiar.

K. T.: La visión desde diferentes partes del mundo también enriquece la comprensión global sobre Japón y de ahí podríamos obtener una mejor imagen sobre las relaciones bilaterales entre ambos países. Creo que la situación actual ha cambiado drásticamente con respecto a la anterior al año 2000. En nuestro campo de estudios, a partir de ese año el número de estudiantes que se matricularon en japonés aumentó considerablemente al igual que su nivel. Las publicaciones sobre Japón también se multiplicaron, así que estamos ya dejando atrás aquella queja del embajador japonés del amor no correspondido, y más bien, España es la que podría utilizar la misma expresión con respecto a Japón. Si contamos el número de visitas del Primer Ministro japonés a España queda evidente que los españoles han visitado bastante más Japón que sus homólogos japoneses España. Como comentaba el Embajador Oyarzábal, Japón es un país que atrae mucho y que podemos contar con numerosas visitas españolas de importancia a Japón, pero a la inversa aún no existe el equilibrio que se podría desear.

\section{Conclusión a cargo del Embajador Antonio Oyarzábal}

Las relaciones actuales entre Japón y España se deslizan suavemente en una normalidad de amistad, colaboración y solidaridad modélicas. Nada las enturbia y nuestra presencia mutua en los dos países alcanza cotas admirables. Claro está que siempre queda mucho por hacer, sobre todo en cuanto al conocimiento de nuestros respectivos pueblos se refiere. En este sentido la buena nueva del restablecimiento reciente de la conexión aérea directa entre Madrid y Tokio promete una intensificación clave 
de nuestros intercambios turísticos y con ellos ese más profundo conocimiento de la realidad de ambos. El horizonte se presenta realmente prometedor.

\section{Breve Currículum Vitae de los ponentes:}

Embajador ANTONIO DE OYARZABAL MARCHESI

Puestos en el extranjero: Londres, Quito-Ecuador, Tokio, Copenhague y Washington DC. (1996-2000). Embajador en Japón 1990-1994.

Como político fue Gobernador de Tenerife y de Guipúzcoa.

Ex Vicepresidente del Real Instituto Elcano de Estudios Internacionales y Estratégicos. (2001 a 2017) Sigue como patrono y es patrono fundador.

Publicaciones:

(2017) Recuerdos políticos. Madrid: Colección La valija diplomática, Cuadernos del Laberinto.

Embajador JUAN LEÑA CASAS

Puestos en el extranjero: La Haya, Tokio, Beijin, Tokio, Argel, Seúl. 2 veces en Japón (19801984, Embajador: 1999-2003)

Colabora con el Instituto Complutense de Estudios Internacionales.

Publicaciones:

(2015) La Historia de la Politica Exterior Española en los siglos XX y XXI. Madrid: CEU Ediciones.

(2018) El papel de España en la Nueva Ruta de la Seda. Madrid: Aranzadi.

Embajador ARTURO PÉREZ MARTÍNEZ

Puestos en el extranjero: Los dos primeros destinos en Japón. (1977-1980, 1981-1984)

Washington DC, Ottawa, Sydney, Viena, Dacca (Bangladesh 2008-2011), Berna.

Los viajes a Japón tanto oficiales como privados suman un total de unos sesenta hasta la fecha. Ha viajado desde el estrecho de Sōya hasta Okinawa.

Publicaciones:

(2000) Las relaciones diplomáticas entre España y Japón. Madrid: Cuadernos de apoyo, Publicaciones UAM.

(2018) Aspectos de Japón vistos por un diplomático español. Gijón: Satori Ediciones. 